\title{
The Effect of Long-Term X-Ray Exposure on Human Lymphocyte
}

\author{
Taqi A. H. ${ }^{\text {*, }}$, Faraj K. A. ${ }^{2}$, Zaynal S. A. ${ }^{1}$
}

\begin{abstract}
The aim of the paper is to investigate effects of long term $\mathrm{x}$-ray exposure on the human lymphocyte, reactive lymphocyte parameters and morphology of lymphocytes in $\mathrm{x}$-ray technicians at Kirkuk hospitals. The study included 54 apparently healthy male $\mathrm{x}$-ray technicians were matched with another 54 apparently healthy control to show any alteration in the lymphocytes, reactive lymphocytes and morphology. The investigated samples were divide into two groups depending on the work experience and working hours per day. The samples were tested for hematological parameters by complete blood cells count $(\mathrm{CBC})$. The results showed that strong significant $(\mathrm{P}<0.0001)$ increasing was recorded for the reactive lymphocytes in all groups of the diagnostic technicians compared with their controls and significantly increasing of lymphocytes observed for some groups. It was concluded that chronic exposure of x-ray can vary lymphocyte and reactive lymphocyte parameters significantly and working hours per day have discernible effects on lymphocyte morphology.
\end{abstract}

Keywords

X-Ray Exposure, Lymphocyte, Reactive Lymphocyte

\section{Introduction}

X -ray is electromagnetic radiation produced outside of a nucleus. It has an energy lower than $\gamma$-ray. X-ray mainly is produced arizing radiation can ionize atoms by removing an electron from their orbits producing ions with positive charge and free electron with negative charge. Ionizing radiation includes the radiation that comes from both natural and man-made radioactive materials [1].

Both low and high doses of ionizing radiation can harm living cells depending on the amount of the dose, dose rate, sex, age, and the type of the target. If the ionizing radiation interacts directly with critical targets for example with DNA, the mechanism is called direct interaction. The process by which ionized radiation interacts with water inside a cell, producing both ions and free radicals is called indirect interaction [2].

Health physics, radiological health, or radiological engineering are concepts used in the field of public health and environmental health engineering which deal with the use of ionizing and nonionizing radiation safely to avoid any biological effects of the radiation on humans. The health physicist is responsible for safety aspects in the design of processes, equipment, and facilities utilizing radiation sources and the safe disposal of radioactive waste so that radiation exposure of personnel will be minimized and will at all times have acceptable limits; they must keep personnel and the environment under constant surveillance in

${ }^{1}$ Department of Physics, College of Science,

Kirkuk University, Kirkuk, Iraq

${ }^{2}$ Department of Phys-

ics, College of Science,

University of Sulaimani,

Kurdistan Region-Iraq

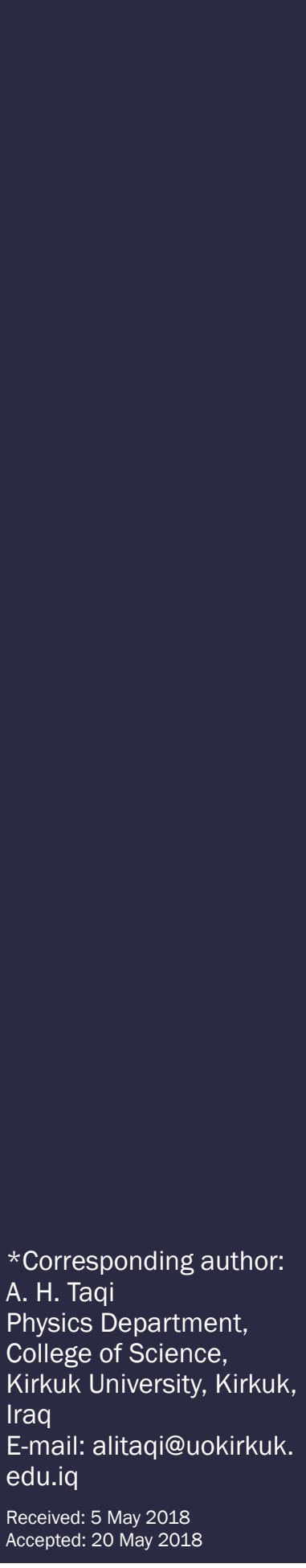


order to ascertain that these designs are indeed effective. If control measures are found to be ineffective or if they break down, the health physicist must be able to evaluate the degree of hazard and make recommendations regarding remedial action [2].

All cells and tissues of human body do not have the same radiosensitivity; some of them are radiosensitive while others are radioresistance [3]. Hematopoiesis is one of the most radiosensitive systems to radiation. It was considered that peripheral blood count is suitable to use as bio indicator to estimate damage from ionizing radiations [4].

Recently, the use of ionizing radiation in medicine has increased,thus it is expected to increase the number of x-ray technicians. Diagnostic technicians not using radiation protection tools for low doses of x-ray during their working days were observed at the hospitals while we did the study.

Any variation of blood cell count in human may lead to suspicion of disease. In numerous studies the importance of blood cell count was explained through the effects of partial or total body irradiation on peripheral blood cell count and most of the studies were focused on high dose radiation received accidentally or therapeutically $[5,6]$. While many studies were conducted on the risks of high-dose radiation, the insufficient information on the radiation takes a risk on technicians working at the clinical radiology departments especially the probable change in the basic hematological parameters such as red blood cells, (RBCs), white blood cells (WBCs) and platelets count that can be used in the determination of the harmful effects of $\mathrm{x}$-ray radiation.

The present study is conducted in Kirkuk hospitals and aims to study the long-term effect of x-ray on technicians blood while measuring lymphocytes, reactive lymphocytes and their morphology.

\section{Material and Methods}

The sample size was 54 healthy male tech- nicians of x-ray working at Kirkuk hospitals and 54 healthy male selected as the control group. The effects of x-ray on lymphocyte parameters were done in two different ways; the first, the technicians were divided into two groups according to their work experience at the hospital, one of the group has experience (1 to 7) years with average working hours (7 hours/day) and it involves 29 technicians with the average age of 39 years and 29 volunteers with the average age of 35 years, the second group has experience ( 8 to 21 ) years with average working hours (6 hours/day), 25 diagnostic technicians with average age of 41 years and 25 controls with average age of 39 years included.

The second division was depended on the number of working hours per day, in this case the technicians divided into three groups: the first group worked (1 to 6) hours/day, this group is included 13 technicians with the average age of 38 years and 13 controls with the average age of 34 years. The second group worked 7 hours/day, there are 18 technicians with the average age of 42 years and 18 controls with the average age of 32 years participated. The last group worked (8 to 12) hours/ day and 23 technicians with average age of 40 years and 23 controls with the average age of 34 years.

The purpose of the study was explained to all the participants. Two $\mathrm{ml}$ of blood was drawn from each participant and transfer to an EDTA tube. The samples were tested for hematological parameters by complete blood cells count (CBC) analyzer (Alpha Swelab, Sweden) to show any variation of lymphocytes and reactive lymphocytes between the groups.

\section{Results}

Table 1 represents the measured data of the lymphocytes in controls and x-ray technicians for different exposure time. By comparing with the controls, significantly increasing value $(p=0.0231)$ of lymphocytes was observed for the group getting working experience (1- 
Table 1: Mean and standard deviation (SD) of Lymphocytes count for the control groups and $\mathrm{x}$-ray technicians.

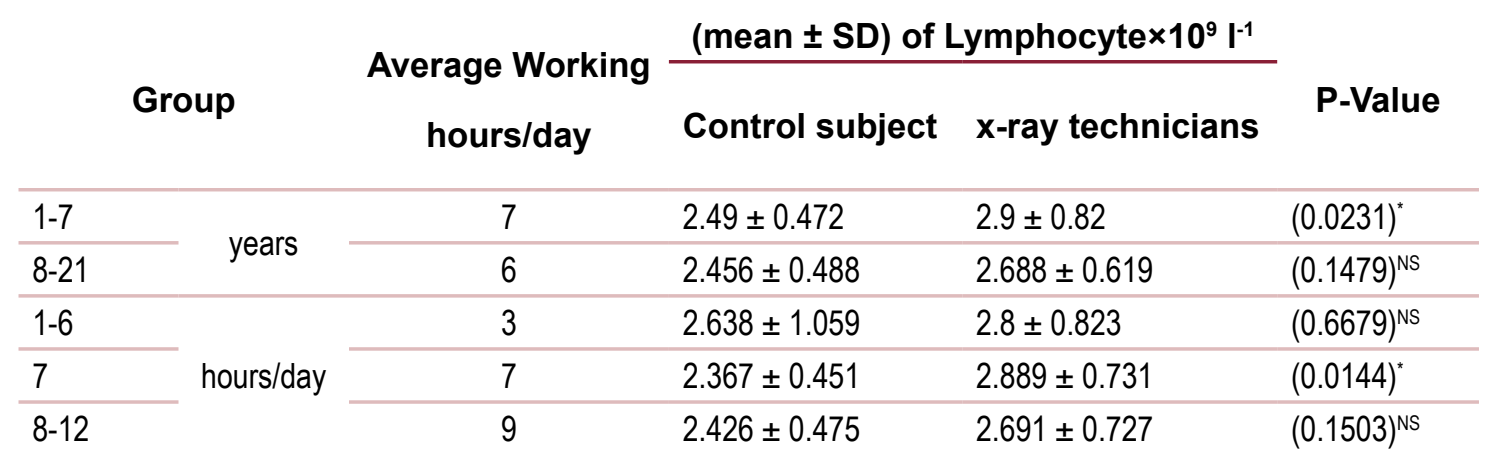

Ns Non Significant, ${ }^{*}<0.05=$ Significant

7) years with average 7 hours/day. While, significantly increasing value $(\mathrm{p}=0.0144)$ of lymphocytes was observed for the second group working 7 hours/day. The lymphocytes count increased slightly in the other groups.

Table 2 represents the measured data of the reactive lymphocytes in controls and x-ray technicians for different exposure time. Highly significant increasing value was observed for reactive lymphocytes $(\mathrm{P}=<0.0001)$ for all the groups in comparing with their control. Figures 1 and 2, show reactive lymphocytes for $\mathrm{x}$ ray technicians according to work experience compared with the lymphocyte. Changes in the lymphocytes morphology were observed clearly.

\section{Discussion}

Effects of ionizing radiations on blood cells have been well documented and it is assumed that the effects contribute to hematopoietic syndrome which is observed in animals and humans after total body irradiation [7]. Diagnostic technicians may be exposed to low doses of x-ray during their work especially if they do not obey the radiation protection tools while we were observing them at the hospital in which we had done our study. While exposure to radiation for the technicians during individual procedure is low, but an occupational hazard increases from accumulative effects of exposure over a time (stochastic effects). Exposure from daily procedures over a long time

Table 2: Mean and standard deviation (SD) of Reactive lymphocytes count for the control groups and x-ray technicians.

\begin{tabular}{|c|c|c|c|c|c|}
\hline \multirow{2}{*}{\multicolumn{2}{|c|}{ Group }} & \multirow{2}{*}{$\begin{array}{c}\text { Average Working } \\
\text { hours/day }\end{array}$} & \multicolumn{2}{|c|}{ (mean \pm SD) Reactive lymphocyte } & \multirow[b]{2}{*}{ P-Value } \\
\hline & & & Control & x-ray technicians & \\
\hline $1-7$ & \multirow{2}{*}{ years } & 7 & $1.03 \pm 1.18$ & $8.59 \pm 6.2$ & $(<0.0001)^{* *}$ \\
\hline $8-21$ & & 6 & $0.76 \pm 0.93$ & $5.8 \pm 4.29$ & $(<0.0001)^{* *}$ \\
\hline $1-6$ & \multirow{3}{*}{ hours/day } & 3 & $1 \pm 1.08$ & $5.31 \pm 3.25$ & $(<0.0001)^{* *}$ \\
\hline 7 & & 7 & $0.94 \pm 1$ & $8.44 \pm 5.834$ & $(<0.0001)^{* *}$ \\
\hline $8-12$ & & 9 & $0.78 \pm 0.95$ & $7.52 \pm 6.18$ & $(<0.0001)^{* *}$ \\
\hline
\end{tabular}




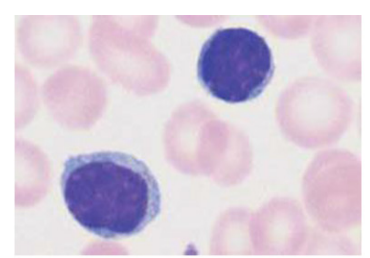

(a)

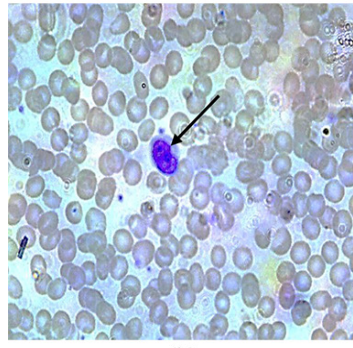

(b)

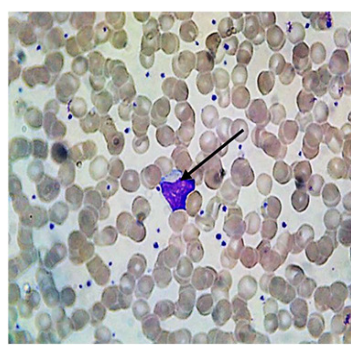

(d)

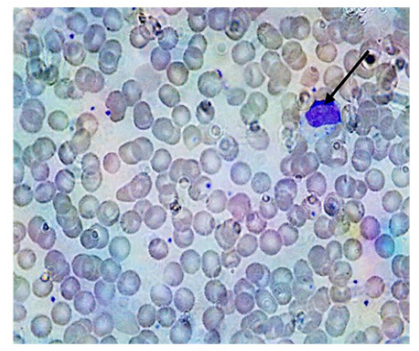

(c)

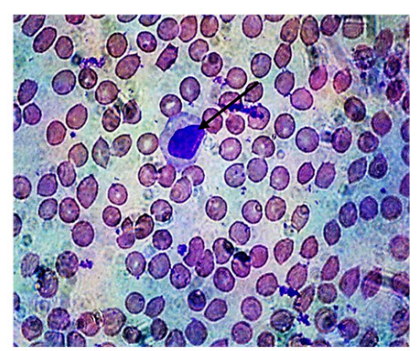

(e)
Figure 1: a) Lymphocyte of a control; b) Reactive lymphocyte of diagnostic technicians work 1 years; c) Reactive lymphocyte of diagnostic technicians work 11 years; d) Reactive lymphocyte of diagnostic technicians work 15 years; e) Reactive lymphocyte of diagnostic technicians work 16 year.

may cause serious, long-term and possibly fatal adverse health consequences [8].

In this study the investigated samples were divided into groups depending on their work experience and daily hours working. Highly significant increasing value was observed for the reactive lymphocytes parameter in all groups compared with the controls while significant increasing value of lymphocytes for the groups (1-7) years and 7 hours/day was observed only. This means that the chronic exposure to x-ray can alter lymphocytes and reactive lymphocytes of the technicians. A slight increase in lymphocytes in the groups $(8-21)$

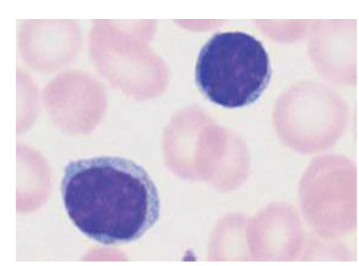

(a)

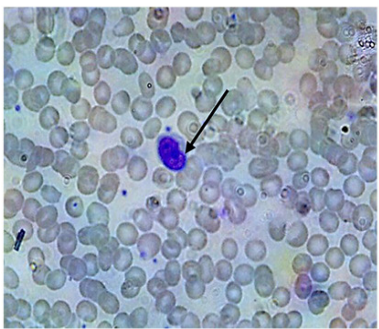

(b)

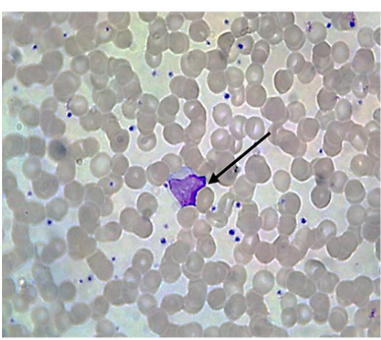

(d)

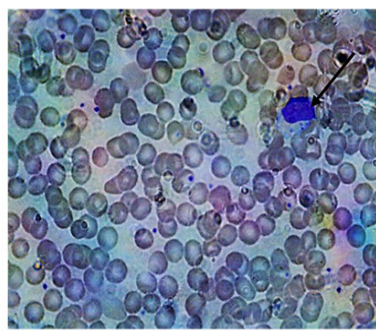

(c)

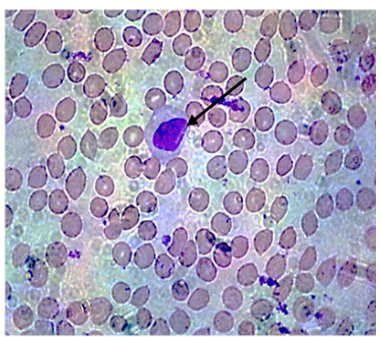

(e)
Figure 2: a) Lymphocyte of a control; b) Reactive lymphocyte of diagnostic technicians works 1 hours; c) Reactive lymphocyte of diagnostic technicians works 2 hours; d) Reactive lymphocyte of diagnostic technicians works 8 hours; e) Reactive lymphocyte of diagnostic technicians works 10 hours.

years with average 6 hours/day, (1-6) hours/ day with average 3 hours and (8-12) hours/day with average 9 hours are also recorded. The effect of radiation on reactive lymphocytes was greater than that of lymphocyte, this may be due to the radio-sensitivity of lymphocytes which are less than that of reactive lymphocytes and the repair mechanisms of lymphocytes is carried out faster than that of reactive lymphocytes.

Saman Shahid et al. showed the parameters: hemoglobin $(\mathrm{Hb})$, white blood cells (WBC), platelet (PLT), hematocrit (HCT), mean corpuscular hemoglobin $(\mathrm{MCH})$, mean cell he- 
moglobin concentration (MCHC) and neutrophil decreased while only two parameters red blood cells (RBC) and lymphocytes increased after exposure to low-dose long-term natural terrestrial ionizing radiation [9]. There is a good match between our investigated results and this study since the significantly increasing value in lymphocytes of the x-ray technicians was observed.

The immunity of the workers can be affected by the chronic exposure to ionizing radiation [10]. Reduction and re-constitutive capacity of hematopoietic stem cells depend on the absorbed doses [11, 5].

In our study, we clearly observed the change in morphology of the lymphocytes of x-ray technicians. Studies on the effects of ionizing radiation on morphology of lymphocytes are limited while some studies conducted on RBC cells. Potential applications have been reviewed by Green stock et al. to correlate membrane damage to observe doses of radiation [12], Shish kina et al. concluded that exposures to low doses of gamma and x-rays showed a high sensitivity of characteristics of the lipid metabolism in erythrocyte [13]. Allehyanim et al. studied the effects of $\gamma$-rays in the dose rate range 0-5.6 Gy on RBCs membrane solubilization of rat's erythrocytes using sodium dodecyl sulfate (SDS). The results demonstrated a shift in the detergent critical concentration of irradiated dose. Blood films for in-vivo rats showed irregular shaped red blood cells, while those photos graphed 10 days after irradiation showed some sort of repair [14].

\section{Conclusion}

Based on the results, It can be concluded that both lymphocyte and reactive lymphocytes parameters of x-ray technicians significantly altered by the chronic exposure to x-ray and the number of working hours per day has discernible effects on lymphocyte morphology. The parameter lymphocytes increased significantly and high-significant increasing value was recorded for the parameter reactive lymphocytes. The x-ray technicians informed about the results and explained the importance of using radiation protection tools in order to avoid any overexposure during their daily lives.

\section{Acknowledgment}

The authors would like to acknowledge all xray technicians whom participate in this study and the Kirkuk hospitals for kindly permission in implementing the project.

\section{Conflict of Interest}

\section{None}

\section{References}

1. Canadian Nuclear Safety Commission. Introduction to Radiation. Ottawa: Canadian Nuclear Safety Commission; 2012.

2. Cember H, Johnson TE. Introduction to Health Physics. 4th ed. New York: McGraw-Hill Education; 2008.

3. Shafiee M, Hoseinnezhad E, Vafapour H, Borzoueisileh S, Ghorbani M, Rashidfar R. Hematological findings in medical professionals involved at intraoperative fluoroscopy. Global Journal of Health Science. 2016;8:232.

4. Rozgaj R, Kašuba V, Šentija K, Prlić I. Radiationinduced chromosomal aberrations and haematological alterations in hospital workers. Occup Med. 1999;49:353-60.

5. Littlefield L, Joiner E, Colyer S, Ricks R, Lushbaugh C, Hurtado-Monroy R. The 1989 San Salvador 60Co radiation accident: cytogenetic dosimetry and follow-up evaluations in three accident victims. Radiat Prot Dosimetry. 1991;35:115-23.

6. Datta N, Chander S, Rath G. Haematological alterations in patients undergoing high dose rate radiotherapy by linear accelerator. The Indian journal of medical research. 1986;83:298-300.

7. Taqi Ali H, Faraj Kharman A, Zaynal Sarah A, Hameed Ahmed M, Mahmood Abd-Alkader A. Effects of occupational exposure of $x$-ray on hematological parameters of diagnostic technicians. Radiation Physics and Chemistry. 2018; 147: 45-52.

8. ORSIF. Occupational Exposure to Ionizing Radiation in Interventional Fluoroscopy: Severity of Adverse Effects of a Growing Health Problem. Washington: Organization for Occupational Radiation 
Safety in Interventional Fluoroscopy, 2015.

9. Shahid S, Chaudhry MN, Mahmood N, Sheikh S. Impacts of Terrestrial Ionizing Radiation on the Hematopoietic System. Polish Journal of Environmental studies. 2015;24:1783-94.

10. Perkins SL. Examination of the blood and bone marrow. In: Wintrobes clinical hematology. Lee R, Foerster J, Leukens J, Paraskervas F, Greer JP, Rodgers GM, editors. Philadelphia: Lippincott Williams and Wilkins; 1999.

11. Ward E, Hornung R, Morris J, Rinsky R, Wild D, Halperin W, et al. Risk of low red or white blood cell count related to estimated benzene exposure in a rubberworker cohort (1940-1975). Am J Ind Med. 1996;29:247-57. doi: 10.1002/(SICI)1097-
0274(199603)29:3<247::AID-AJIM4>3.0.C0;2-N. PubMed PMID: 8833777.

12. Greenstock CL, Trivedi A. Biological and biophysical techniques to assess radiation exposure: a perspective. Prog Biophys Mol Biol. 1994;61:81-130. PubMed PMID: 8029472.

13. Shishkina LN, Kushnireva EV, Smotriaeva MA. A new approach to assessment of biological consequences of exposure to low-dose radiation. Radiats Biol Radioecol. 2004;44:289-95. PubMed PMID: 15287259.

14. Allehayanim S, Monem S. Membrane solubilization and hemoglobin gelation as biomarker of radiation exposure to gamma-rays. Egyptian Biophysics Journal. 2003;9:234-44. 